TI 2011-155/3

Tinbergen Institute Discussion Paper

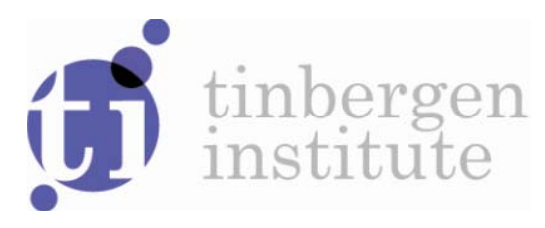

\title{
Measurement of Inequity in Health Care with Heterogeneous Response of Use to Need
}

Ellen Van de Poell

Eddy Van Doorslaer ${ }^{2}$

Owen O'Donnel/2

1 Health Policy \& Management, Erasmus University Rotterdam;

2 Erasmus School of Economics; Erasmus University Rotterdam, and Tinbergen Institute. 
Tinbergen Institute is the graduate school and research institute in economics of Erasmus University Rotterdam, the University of Amsterdam and VU University Amsterdam.

More TI discussion papers can be downloaded at http://www.tinbergen.nl

Tinbergen Institute has two locations:

Tinbergen Institute Amsterdam

Gustav Mahlerplein 117

1082 MS Amsterdam

The Netherlands

Tel.: +31(0)205251600

Tinbergen Institute Rotterdam

Burg. Oudlaan 50

3062 PA Rotterdam

The Netherlands

Tel.: +31(0)10 4088900

Fax: $+31(0) 104089031$

Duisenberg school of finance is a collaboration of the Dutch financial sector and universities, with the ambition to support innovative research and offer top quality academic education in core areas of finance.

DSF research papers can be downloaded at: http://www.dsf.nl/

Duisenberg school of finance

Gustav Mahlerplein 117

1082 MS Amsterdam

The Netherlands

Tel.: +31(0)20 5258579 


\title{
Measurement of inequity in health care with heterogeneous response of use to need
}

\author{
Ellen Van de Poel ${ }^{\mathrm{a}, 1}$, Eddy Van Doorslaer ${ }^{\mathrm{a}, \mathrm{b}, \mathrm{c}}$, Owen O’Donnellb,c,d
}

\begin{abstract}
We propose a method of measuring and decomposing inequity in health care utilisation that allows for heterogeneity in the use-need relationship. This makes explicit inequity that derives from unequal treatment response to variation in need, as well as that due to differential effects of non-need determinants. Under plausible conditions concerning heterogeneity in the use-need relationship and the distribution of need, existing methods that impose homogeneity will underestimate pro-rich inequity. This prediction is confirmed for four low-middle income Asian countries.
\end{abstract}

\section{Key Words}

health care, equity, decomposition,

JEL codes: D63, I14

\section{Acknowledgements}

This work was funded through EU-FP7 research grant HEALTH-F2-2009-223166HEFPA on "Health Equity and Financial Protection in Asia". Comments received on earlier versions of this paper at workshops held in Siem Reap (Cambodia), at CORE (UCL, Louvain-la-Neuve, Belgium) and at iHEA (Toronto, Canada) are gratefully acknowledged. Also many thanks to Joseph Capuno and to Tom Van Ourti for their valuable feedback.

\footnotetext{
${ }^{1}$ E Van de Poel, Institute of Health Policy and Management, Erasmus University Rotterdam, PO Box 1738, 3000 DR Rotterdam, The Netherlands, Tel: +31104089046, E-mail: vandepoel@,bmg.eur.nl (corresponding author); O O'Donnell, E-mail: ood@uom.gr; E Van Doorslaer, E-mail: vandoorslaer@ese.eur.nl ${ }^{a}$ Institute for Health Policy and Management, Erasmus University, Rotterdam, NL

${ }^{\mathrm{b}}$ Erasmus School of Economics, Erasmus University, Rotterdam, NL

c Tinbergen Institute, Erasmus University, Rotterdam, NL

${ }^{\mathrm{d}}$ University of Macedonia, Thessaloniki, GR
} 


\section{Introduction}

Most empirical research on equity in health care delivery examines horizontal equity defined as equal treatment for equal need irrespective of characteristics, such as socioeconomic status (SES), across which variation in health care is claimed to be illegitimate (e.g. Bago d’Uva et al., 2009; Goddard and Smith, 2001; Lu et al., 2007; Van Doorslaer et al., 2004; Wagstaff and Van Doorslaer, 2000). In practice, treatment is measured by utilisation of health services and need by health indicators and demographics. Horizontal inequity is often identified by comparing the deviation of the actual health care distribution from that which would arise if utilisation were driven by need alone (Wagstaff and Van Doorslaer, 2000). The counterfactual is simulated by estimating a model of health care utilisation and using this to make predictions on the basis of variation in need indicators with non-need determinants held constant (e.g. Van Doorslaer et al., 2004). The model employed is additively separable in need and non-need factors, which has two important consequences (Fleurbaey and Schokkaert, 2009; Gravelle, 2003). First, variation in the responsiveness of use to need is not explicitly taken into account. While the measure of inequity does indirectly capture inequality in utilisation that derives from differential response of use to need by SES (or whatever is the characteristic in relation to which equity is assessed), this potentially important source of inequity cannot be made explicit in its decomposition based on an additively separable model (Van Doorslaer et al., 2004). Second, if there is heterogeneity in the use-need relationship, then estimates from a model that imposes homogeneity will reflect some average. Using this to predict legitimate variation in utilisation implies that the average response of use to need is an acceptable vertical equity norm - the appropriate unequal treatment of unequals. Particularly in countries where the resource constraint on health spending is extremely tight, the average response of utilisation to need likely falls far short of providing effective treatments. Using the average response will understate the need and, consequently, the degree of inequity experienced by population groups in which need is concentrated.

We correct both deficiencies by measuring and decomposing inequity using an empirical model of health care utilisation that allows the need response to vary with SES. Building on the inequality decomposition in the presence of heterogeneity introduced by Jones and López Nicolás (2006), we show how the standard measure of horizontal inequity based on the concentration index can be corrected to better reflect the variation in utilisation that is justified by inequality in the distribution of need. We conjecture that 
in most cases this will result in an upward revision to measured inequity against deprived groups. The method requires the choice of a reference population group that is presumed to come closest to realising vertical equity. That is, the response of utilisation to need in this group is considered most appropriate. Legitimate variation in utilisation is estimated by feeding the actual distributions of need indicators into the use-need relationships holding in the reference group. Part of the inequitable variation in utilisation is due to SES-related departure from the use-need relationship of the reference group. This component of inequity is clearly identified in the decomposition alongside that arising from differences in use for a given level of need that are directly or indirectly related to SES.

Our main contribution is to demonstrate how the Jones and López Nicolás, (2006) decomposition of the concentration index can be used to better measure and characterize inequity in health care utilisation. The message of the paper is related to, but distinct from, that of Sutton (2002), who argues that even if horizontal equity is satisfied, in the sense of there being no socioeconomic-related variation in utilisation at each level of need, socioeconomic groups in which need is concentrated will still be disadvantaged if there is vertical inequity in the form of higher levels of need not receiving sufficiently greater treatment resources. He identifies the implications for socioeconomic-related inequity of a homogeneous but unfair use-need relationship. We allow for heterogeneity in the use-need relationship, which may be vertically equitable for some but not for all. The poor can then be disadvantaged not only because they are in greater need and treatment is insufficiently responsive to medical need but also because this response is more muted among the poor than it is among the rich. Huber (2008) does allow for heterogeneity in decomposing inequality in health care use but, unlike ours, her method is path dependent. Contributions of factors depend on the order in which they are switched between distributions.

We illustrated our method using data from the World Health Surveys (WHS) for the Philippines and, in less detail, three other Asian countries (Bangladesh, India, and Malaysia). The WHS have extensive indicators of health status, which are used to proxy medical need. Developing countries are chosen because the assumption of the standard methodology that the average use-need relationship is an appropriate one from which to predict legitimate variation in utilisation is particularly implausible in this context. While this assumption might be reasonable in developed countries with fairly comprehensive benefit packages and close to universal coverage, it seems a much more contentious in developing countries where typically only a minority of the population is likely to receive 
care according to need. No doubt this explains why, hitherto, there has been little attempt to measure inequity, as opposed to inequality, in low and middle income settings (Van Doorslaer and O’Donnell, 2010).

In what follows we first present a methodological framework that relates the existing measurement and decomposition tools to the theoretical literature on fairness before extending the decomposition to allow for heterogeneity in the use-need relationship. We then apply the methodology to the Philippines' data before comparing the results with those for the other three countries. We end with an assessment of the virtues and limitations of the method.

\section{Established measurement of inequity in health care utilisation}

\section{The conventional approach}

Our aim is to measure and explain socioeconomic-related inequity in the utilisation of health care. The dominant approach in the health economics literature has been to restrict attention to horizontal inequity, defined as unequal treatment for equal need, and to use the concentration index to quantify socioeconomic inequalities in health care use standardized for the distribution of need, which is proxied by indicators of health status and demographics (Wagstaff and Van Doorslaer, 2000). The concentration index can be calculated as

$C_{y}=\frac{2 \operatorname{cov}\left(y_{i}, R_{i}\right)}{\mu_{y}}$

where $y_{i}$ is a measure of individual $i$ 's utilisation of health care, $\mu_{h}$ is the mean of $y_{i}$ and $R_{i}$ is the individual's fractional rank in the distribution of the variable used to proxy socioeconomic status.

If $y_{i}$ is presumed to be a linear and additively separable function of a set of $J$ need indicators $x_{j}$ and $K$ non-need variables $z_{k}$,

$y_{i}=\alpha^{P}+\sum_{j=1}^{J} \beta_{j}^{P} x_{j i}+\sum_{k=1}^{K} \gamma_{k}^{P} z_{k i}+\varepsilon_{i}$

then the concentration index can be written as a weighted average of the concentration indices of the explanatory variables (Wagstaff et al., 2003),

$C_{y}=\sum_{j=1}^{J} \frac{\beta_{j}^{P} \bar{x}_{j} C_{x_{j}}}{\mu_{y}}+\sum_{k=1}^{K} \frac{\gamma_{k}^{P} \bar{z}_{k} C_{z_{k}}}{\mu_{y}}+G C_{\varepsilon}$ 
where $\bar{x}_{j}$ and $\bar{z}_{k}$ are the means of the covariates, and $C_{x_{j}}$ and $C_{z_{k}}$ their concentration indices (with respect to socioeconomic status). $G C(\varepsilon)$ is the generalized concentration index of the errors and reflects the socioeconomic inequality that is left unexplained by the model. ${ }^{1}$

An index of inequity, which hitherto has been interpreted as a measure of horizontal inequity, can be obtained by subtracting the need contributions in (3) from the concentration index,

$I_{1}=C_{y}-\sum_{j=1}^{J} \frac{\beta_{j}^{P} \bar{x}_{j} C_{x_{j}}}{\mu_{y}}$.

This is equal to the Wagstaff and Van Doorslaer (2000) index defined as the concentration index for indirectly need-standardized health care use (Van Doorslaer et al., 2004). The validity of this approach rests on the normative interpretation of the regression coefficients $\beta_{j}^{P}$ as indicating how health care should, and not merely how it does on average, vary with need. It is recognised that measurement of horizontal inequity requires adoption of a vertical equity norm, which has been presented as "on average, the system gets it right” (Van Doorslaer et al, 2000; O’Donnell et al, 2008).

\section{Direct versus Indirect standardisation}

Direct standardisation offers an alternative to the indirect standardisation approach to the identification of inequity. This method gives the hypothetical distribution of health care corresponding to a situation in which there is no variation in need and so utilisation is driven only by non-need factors. Fleurbaey and Schokkaert (2009) connect these methods to the social choice theory of fair allocation. They identify two conditions for defining unfair inequalities in health and health care. Adapted to the present context, the first requires that a measure of inequity in health care use should not reflect variation due to need variables (no influence of legitimate differences). Measures based on directly standardized health care satisfy this since utilisation is predicted with need variables set to some reference values. Fleurbaey and Schokkaert label the resulting inequality direct unfairness. The second condition requires that a measure of zero inequity implies that there is no variation in health care related to non-need variables (compensation). This is satisfied by measures based on the indirectly standardized distribution, which would be

\footnotetext{
${ }^{1}$ In principle, the model can always be defined such that there is no correlation between the errors and SES and so $G C_{\varepsilon}$ is zero (Gravelle, 2003). In application, there can be some correlation between the residuals and SES although this should be minimized with the latter included among the non-zero determinants.
} 
degenerate if non-need factors exert no influence. Fleurbaey and Schokkaert label this approach the fairness gap.

If health care utilisation is additively separable in need and non-need determinants, as in (2), then the two approaches give the same measure of absolute inequality, although measures of relative inequality will differ (Fleurbaey and Schokkaert, 2009). But if the assumption of separability is relaxed, such that the impact of need on utilisation is allowed to depend on socioeconomic status, or other non-need factors, then the two approaches become incompatible even within the domain of absolute inequality; a measure of direct unfairness is no longer identical to a measure of fairness gap. Fleurbaey and Schokkaert argue in favour of the latter approach, and so indirect standardisation: when an individual is not held responsible for his need and the responsiveness of health care to need depends on socioeconomic status, then a measure of inequity should indeed reflect the distribution of need, which direct unfairness measures do not.

\section{Horizontal and vertical inequity}

Most studies have claimed to measure horizontal inequity in health care utilisation. Sutton (2002) concentrates on vertical inequity - treatment resources do not rise sufficiently with medical need such that those in greater need are not fairly prioritized. This begs the difficult question of how an equitable relationship between treatment and need should be defined. Putting this aside, if treatment is considered inadequately responsive to need, then, since need is typically more concentrated among the poor, they will experience more of the vertical inequity. Sutton argues that this should be considered part of socioeconomic inequity. Even if horizontal equity was satisfied - treatment did not vary with SES at any level of need - there would be socioeconomic inequity if there was vertical inequity against those in greater need who were disproportionately poor. While vertical inequity is obviously a dimension of inequity, whether it should be considered part of socioeconomic inequity depends on the reasons why need is correlated with SES (Fleurbaey and Schokkaert, 2011, p.34). If the poor are sicker because of their poverty, which seems plausible, then the inadequate treatment of those in greater medical need is indeed part of the unfairness experienced by the individual that is ultimately due to his or her low SES.

Sutton considered the consequences of the use-need relationship being suboptimal but maintained its homogeneity with respect to SES. When the response of use to need varies with SES, then neither vertical nor horizontal equity can hold. With heterogeneity, the use-need relationship can only be vertically equitable, if at all, for some 
SES groups. Utilisation can only respond to need differentially by SES if at some level of need there is variation in utilisation and so horizontal equity is not satisfied. Interactions between need and non-need determinants of health care also make all measures dependent on chosen reference points. Socioeconomic variation in use for a given level of need will depend on the level to which need is set in direct standardisation, which is therefore an inappropriate approach to the measurement of horizontal inequity (Fleurbaey and Schokkaert, 2011). The measured fairness gap implemented though indirect standardisation will depend upon the reference socioeconomic status and use-need relationship chosen to predict needs-based utilisation.

In the next sub-section we explain how heterogeneity in the use-need relationship can be taken into account in a concentration index measure of inequity, and how this both improves the adjustment for need differences and makes explicit more dimensions of inequity than are evident with the conventional inequity index (4).

\section{Proposed measurement of inequity in health care utilisation}

\section{Decomposition with heterogeneity}

Let each individual belong to one of $G$ population groups distinguished by characteristics that potentially condition the extent to which health care utilisation responds to need, as well as non-need determinants. We will consider the choice of characteristics that distinguish these groups below. Model (2) is generalized to one that permits complete parameter heterogeneity across the $\mathrm{G}_{\text {groups }}{ }^{2}$,

$$
y_{i}=\alpha_{g}+\sum_{j=1}^{J} \beta_{j g} x_{j i}+\sum_{k=1}^{K} \gamma_{k g} z_{k i}+u_{i}, \quad i \in g, \quad g=1, \ldots . G
$$

Following Jones and López Nicolás (2006), the concentration index can then be decomposed into a part that derives from socioeconomic inequality in the distribution of the covariates, and a part deriving from socioeconomic inequality in their effects,

$$
\begin{aligned}
C_{y}= & \sum_{j} \frac{\beta_{j}^{P} \bar{x}_{j} C_{x_{j}}}{\mu_{y}}+\frac{2}{\mu_{y} N} \sum_{j} \sum_{i} x_{j i}\left(\beta_{j g}-\beta_{j}^{P}\right)\left(R_{i}-1 / 2\right)+ \\
& \sum_{k} \frac{\gamma_{k}^{P} \bar{z}_{k} C_{z_{k}}}{\mu_{y}}+\frac{2}{\mu_{y} N} \sum_{k} \sum_{i} z_{k i}\left(\gamma_{k g}-\gamma_{k}^{P}\right)\left(R_{i}-1 / 2\right)+ \\
& \frac{2}{\mu_{y}} \operatorname{cov}\left(\alpha_{g}, R_{i}\right)+\frac{2}{\mu_{y}} \operatorname{cov}\left(u_{i}, R_{i}\right)
\end{aligned}
$$

\footnotetext{
2 Jones and López Nicolás (2006) allow the parameters to be fully heterogeneous across individuals. In practice, this is infeasible without panel data with a very long span. In their application, they allow for group specific heterogeneity, as here. Note that parameter heterogeneity can be restricted to a subset of the covariates.
} 
in which $\beta^{P}, \gamma^{P}$ are the parameters from the pooled model (2). The first and third terms in (6) represent the contributions of the need and non-need variables to socioeconomic inequality in health care use, assuming that their effects are constant over the population, as in (3). These are referred to as homogeneous contributions in the remainder. The second and fourth terms quantify the contribution of heterogeneity in the parameters around the pooled values for the need and non-need variables. Loosely, one can think of these terms as the covariance between the parameter and socioeconomic rank weighted by the respective covariate. If the parameter is positive and increasing with rank, then this term will add to pro-rich bias in the distribution of health care. For example, if need has a larger positive impact on utilisation in higher socioeconomic groups, for any distribution of need, this will bias the distribution of health care in favour of the rich relative to a situation in which there was no heterogeneity in the impact of need on use. The fifth term is the covariance between the group-specific intercepts and socioeconomic rank, and reflects the direct contribution of group differences in health care utilisation to SES related inequality. ${ }^{3}$ Finally, the sixth term corresponds to the unexplained part of socioeconomic inequality in health care use. This will be smaller than the corresponding term in (3) due to the additional explanatory power provided by the heterogeneous parameters.

Huber (2008) also suggests a decomposition of inequalities in health care use that allows for parameter heterogeneity. She quantifies the contributions of covariates and of parameter heterogeneity to the concentration index by sequentially neutralizing the contributions of other covariates and parameters, predicting health care and computing the concentration index for the simulated distribution. This does not require a linear model such as (2), but non-linearity does introduce approximation errors and, given the stepwise nature of the approach, the magnitude of these errors, as well as the contributions, will depend on the order in which covariates and parameters are switched. ${ }^{4}$ There is an analogy between the decomposition in (6) and the Blinder-Oaxaca decomposition (Blinder, 1973; Oaxaca, 1973) of an outcome gap between two population groups into a part deriving from differences in the distribution of determinants and a part due to differences in their effects. The advantage of decomposing a concentration index is that it measures inequality across the entire socioeconomic distribution instead

\footnotetext{
${ }^{3}$ As Jones and López Nicolás (2006) state, this interpretation requires the assumption that the intercept of the pooled model provides a measure of the central tendency of the group specific intercepts.

4 Van Doorslaer et al (2004) prove that the neutralization approach is only exact in linear additive models.
} 
of the gap between two groups. Furthermore, the decomposition in (6) is also more general in that it allows the effects of covariates to vary over more than two groups.

\section{Measurement of inequity with heterogeneity}

If one wants to make normative statements about which components of (6) can be considered inequitable, it is necessary to choose the set of need parameters that are considered to represent the most appropriate relationship of utilisation to need. That is, one must choose the population group that comes closest to realizing vertical equity in the response of health care to differential need. Assuming it is possible to identify such a group, expansion of the second term in (6) through addition and subtraction of the need effects specific to the reference group gives,

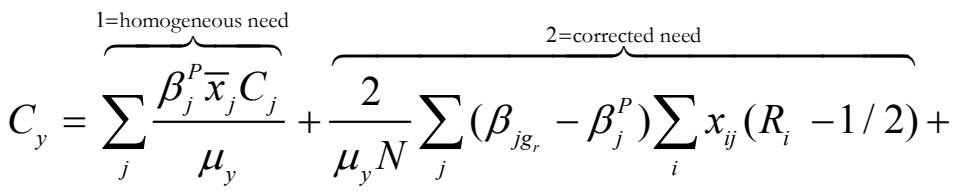

$$
\begin{aligned}
& \overbrace{\frac{2}{\mu_{y} N} \sum_{j} \sum_{i} x_{j i}\left(\beta_{j g}-\beta_{j g_{r}}\right)\left(R_{i}-1 / 2\right)}^{3=\text { discrimination }}+\overbrace{\sum_{k} \frac{\gamma_{k}^{P} \bar{z}_{k} C_{k}}{\mu_{y}}}^{4=\text { homogeneous non-need }}+ \\
& \overbrace{\frac{2}{\mu_{y} N} \sum_{k} \sum_{i} z_{k i}\left(\gamma_{k g}-\gamma_{k}^{P}\right)\left(R_{i}-1 / 2\right)}^{5=\text { heterogeneity in non-need effects }}+\overbrace{\frac{2}{\mu_{y}} \operatorname{cov}\left(\alpha_{g}, R_{i}\right.}^{6=\text { group differences }})+\overbrace{\frac{2}{\mu_{y} \operatorname{cov}\left(u_{i}, R_{i}\right)}}^{\text {7=unexplained }}
\end{aligned}
$$

where $\beta_{j g_{r}}$ are the parameters of the need variables for the reference group. The contributions of the heterogeneity in the need effects are now broken down into two parts that we label corrected need and discrimination. The first re-weights socioeconomic inequality in each need variable by the difference between its effect in the reference group and its average effect, as represented by the pooled parameter. This represents an adjustment to the inequality in utilisation that is justified by the unequal distribution of need. It indicates the bias in need-predicted utilisation that would arise if predictions were obtained from a homogeneous parameter model, as in (2) and (3), rather than using the vertically more equitable use-need relationship operating in the reference group. This term is not part of inequity ${ }^{5}$. Added to the first term, it gives the legitimate variation in utilisation. The third term gives the extent to which the different responsiveness of the health care system to the needs of any subgroup $g$, as compared to the reference group, contributes to socioeconomic inequality in health care use. We refer to this as

\footnotetext{
${ }^{5}$ Note that the first term and the second part of the second term cancel out, as becomes clear in (8).
} 
discrimination as it indicates how the treatment response to need in some groups is less appropriate than it is in the reference.

To help clarify interpretation, consider the following (very common) scenario in which need is more concentrated among the poor, health care use responds positively to need, but the effect increases with income, and is considered most appropriate for the top income quintile. The concentration index of health care with respect to income is estimated and separate regression models are estimated for each income quintile with the top used as the reference category for the decomposition. In this situation, the first term in (7) is negative, indicating that the distribution of need is driving pro-poor use of health care. But the extent to which the poor should be making greater use of health care due to their need is understated by this term. It should be corrected by the second term, which is negative given the concentration of need among the poor and the larger impact of need on utilisation in the top income quintile. The product of the parentheses in the third term equals zero for the individuals belonging to the top income quintile $\left(\beta_{j g_{r}}=\beta_{j g}\right)$, is negative for individuals between the median and eightieth quantile of the income distribution $\left(\beta_{j g_{r}}<\beta_{j g}\right.$ and $\left.R_{i}-1 / 2>0\right)$ and is positive for those below the median $\left(\beta_{j g_{r}}<\beta_{j g}\right)$ and $\left.R_{i}-1 / 2<0\right)$. As $x_{j i}$ (need) is generally larger among the poor, the third term will be positive, indicating the discrimination against the poor in the health care system that is contributing to pro-rich inequality.

The method requires choice of a characteristic across which heterogeneity is permitted and a reference group. Most straightforward is to allow heterogeneity and measure inequality in relation to the same characteristic - income in the example. But this is not essential. For example, one could measure inequality against income but allow parameter heterogeneity by health insurance coverage. With utilisation rising with coverage, abstracting from moral hazard, those with the most comprehensive insurance could be presumed to get the most appropriate treatment response to medical need and so be used as the reference. The sign of the third term in (7) would be positive if there was positive correlation between income and insurance cover and this would still indicate inequity to the disadvantage of the poor. The normative interpretation of the decomposition would change in the case that the strongest response of utilisation to need is not considered the most appropriate one. For example, it may be that information asymmetries result in the highest income, or the most fully insured, overusing health care even in the extreme sense of the marginal benefit being negative. If some other group were made the reference, then the discrimination term would still be positive, reflecting 
the fact that monotonicity of the marginal effect of need on use with income contributes to inequality. But it would be perverse to label this inequity in favour of the rich since their excess use makes them worse off. This is not a limitation of this particular decomposition. It applies to all measures based on the concentration index, which requires that welfare is monotonic in the variable in which inequality is being measured.

If the grouping characteristic is chosen to be the same as that against which inequality is being assessed, then it is not advised to include the same characteristic among the non-need determinants. The reason is that apparent parameter heterogeneity in relation to this characteristic can simply be due to nonlinearity of the effect. For example, imagine inequality is being assessed against income and heterogeneity is allowed by income quintile. If the health care-income function is concave, then the income effect in the richest quintile will be smaller than that in the bottom. But this is not contributing to the observed inequality. The direct (nonlinear) income effects on income-related inequality in utilisation should simply be picked up through the sixth term of the decomposition.

An index of inequity is given by subtracting all legitimate inequality due to need from the concentration index,

$$
\begin{aligned}
I_{2} & =C_{y}-\sum_{j} \frac{\beta_{j}^{P} \bar{x}_{j} C_{j}}{\mu_{y}}-\frac{2}{\mu_{y} N} \sum_{j}\left(\beta_{j g_{r}}-\beta_{j}^{P}\right) \sum_{i} x_{i j}\left(R_{i}-1 / 2\right) \\
& =\mathrm{C}_{y}-\sum_{j} \frac{\beta_{j g_{r}} \bar{x}_{j} C_{j}}{\mu_{y}}
\end{aligned}
$$

This represents a means of implementing the general approach to a fairness gap measure of inequity in health care sketched by Fleurbaey and Schokkaert (2011, eq.(28)). It differs from (4) by the subtraction of the corrected need effect and so total inequity will differ $\left(I_{2} \neq I_{1}\right)$. If need is negatively correlated with socioeconomic rank and has a stronger impact on utilisation in the reference group than in the pooled population, then this correction term will be negative and $I_{2}>I_{1}$. Pro-rich (pro-poor) inequity is underestimated (overestimated) when the health care that individuals of lower socioeconomic status should be receiving given their need is understated. The decomposition given by equation (7) makes it clear that both $I_{1}$ and $I_{2}$ measure not only horizontal inequity but also what we have labelled discrimination and heterogeneity in non-need effects. The former, represented by term 3 in (7), is the socioeconomic bias in the response of medical care to need. If such heterogeneity exists, then vertical equity cannot hold. The response of medical care to need cannot be simultaneously universally appropriate and heterogeneous. One group may be treated vertically equitably, but then 
at least some of the others are not. The claim that $I_{1}$ is a measure of horizontal inequity (Wagstaff and Van Doorslaer, 2000) is correct only in the case that need and non-need factors are indeed additively separable determinants of health care utilisation.

Health care utilisation is typically measured by a bounded variable - any hospital admissions, number of doctor visits in the last month - and so Erreygers' (Erreygers, 2009) corrected concentration index is a more appropriate measure of socioeconomicrelated inequality. Erreygers and Van Ourti (2011) have recently shown that the corrected concentration index is the only rank-dependent inequality index that simultaneously satisfies the properties of mirror (inequality in use should 'mirror' inequality in non-use) and quasi-absoluteness. ${ }^{6}$ The correction implies that socioeconomic inequalities are measured in absolute rather than relative terms, but leaves the interpretation of the decomposition unchanged. The equivalent of equations 1-8 using the corrected concentration index can be found in Appendix 1.

\section{Data}

Data are from the Philippines component of the World Health Survey (WHS), which was conducted by the World Health Organization in 2002-2003. . The Philippines uses tax revenues to subsidize health insurance for the informal sector and in 1995 established a National Health Insurance Program, called PhilHealth, with the aim of providing universal health insurance coverage by 2010. Coverage has indeed increased, and stands at about $70 \%$ of the population, but has remained quite limited among the poor (Capuno, 2006).

The Philippine data are nationally representative and cover 9472 households. The WHS provides detailed data on health status, allowing better measurement of need than has been realized in most studies of equity in health care utilisation. The information on health care use is somewhat more limited. One section of the questionnaire asks a randomly selected adult household member about his/her last health care visit. A later section asks about the same respondent's inpatient care use in the last five years and - only if the respondent had no inpatient care - about his/her outpatient care use. The information from the first section is clearly limited in the sense that the last health care visit need not be representative of health care use in the last month/year/five

\footnotetext{
${ }^{6}$ Quasi-absoluteness focuses on absolute differences and formally requires that the index should be insensitive to any feasible equal addition to the health care variable. One can construct a rank-dependent inequality measure that focuses on relative differences, but only by abandoning the property of mirror (Erreygers, 2009; Erreygers and Van Ourti, 2011; Wagstaff, 2009)

${ }^{7}$ More information is available at http://www.who.int/healthinfo/survey/en/
} 
years. The second section does distinguish between in- and out-patient care in the last 5 years, but the routing impedes separate analysis of outpatient care use. Therefore, we investigate inequities in the use of any care in the last year (any care) and inpatient use (inpatient) in the last five years. ${ }^{8}$

Need is proxied through a rich array of self-reported health problems and symptoms of chronic illnesses. For each of six medical conditions (arthritis, angina, asthma, depression, psychosis, TB), respondents are asked a series of questions concerning possible symptoms experienced in the last 12 months. Moussavi et al (2007) derived optimal algorithms for the detection of conditions from these questions using Receiver Operating Characteristic (ROC) analyses on the basis of a diagnostic item probability study conducted in seven countries. We use these algorithms to define indicators of the six conditions. Furthermore we use indicators of whether the respondent reports experiencing back pain (back) in the last 30 days and whether s/he reports severe or extreme problems with daily activities (daily), vigorous activities (vigorous), taking care of her/himself (selfcare), pain or bodily discomfort (pain), concentrating or remembering things (cognition), personal relationships (relation), sight (seeing), and sleeping (sleep) (see Table 1). Also included is a dummy variable indicating whether (s)he reports current health as moderate, bad or very bad (badhealth) rather than good or very good. For females, we include an indicator of having given birth in the last year/last 5 years (child1y/child5y) for models of any care and inpatient care respectively. ${ }^{9}$ Indicators are also included for having been involved in an accident (accident), experienced teeth or gum problems (oralprob) and difficulties performing work or household activities (difhh) in the past 12 months. To control for any further unmeasured variation in need with demographics, we include a set of age and sex dummies (F1830, F30-50, F50plus, M1830, M30-50, M50plus).

The non-need determinants of utilisation included are marital status (married), education (noeduc, primeduc, seceduc, higheduc), employment status (govemp, nongovemp, selfemp, empl, notworke) $)^{10}$. Socioeconomic status (SES) is measured by principle components score from analysis of asset ownership and household dwelling characteristics, including

\footnotetext{
${ }^{8}$ Use of any care will be underestimated for respondents who used inpatient care in the last 5 years preceding the survey, but not in the last year, and did use outpatient care in the last year. We somewhat correct for this by switching the any care dummy to 1 if we know from the first section that the respondent had a visit in the last year.

${ }^{9}$ Coded to zero for males.

${ }^{10}$ Health insurance cover is not included because of the usual concerns about potential endogeneity (there is substantial private insurance) and because the estimated coverage rate of $20 \%$ is substantially lower than the official rates of about $70 \%$, (see e.g. Obermann et al., 2006).
} 
sanitation facilities (Filmer and Pritchett, 2001). ${ }^{11}$ In the context of a low middle-income country with limited health insurance cover and substantial transport costs, we hypothesize two important dimensions in which there is heterogeneity in the responsiveness of health care to need: capacity to pay and distance to health facilities. We therefore investigate how health care use responds to health care need across ten population groups defined by combinations of wealth quintiles $\left(Q^{1}-Q^{5}\right)$ and urban/rural location.

\section{Results}

\section{Unequal use of health care in The Philippines}

On average, 29 per cent of the respondents report to have used any care in the last year, while only 16 per cent have used inpatient care in the last 5 years. The corrected concentration (CC) indices of any care and inpatient care equal $0.083(\mathrm{SE}=0.019)$ and 0.059 $(\mathrm{SE}=0.013)$ respectively. This means that health care use is disproportionately more concentrated among the wealthier population groups, and more so in the case of any care. The latter finding might be somewhat unexpected and derives from the CC being a quasi-absolute inequality index.

Table 1 presents means and corrected concentration indices for all independent variables used in the models. The negative indices on the ill-health variables indicate that ill-health is more prevalent among poorer individuals. Education and government employment are more prevalent in wealthier population groups while poor respondents are more likely to be self-employed or self-employers, which is likely to reflect the larger share of agricultural workers in this group. While the proportion of respondents belonging to the richest $\&$ rural and poorest $\&$ urban wealth quintiles are quite small, there still appears sufficient overlap between wealth and urbanicity. By definition, concentration indices of richer (poorer) wealth quintiles are positive (negative).

\section{Heterogeneous effects of covariates on health care use}

In order to establish whether heterogeneity is in the direction anticipated and whether it is reasonable to take the use-need relationship of the highest wealth, urban group as the reference, we regress the utilisation measures on a composite ill-health index (bealthfactor),

\footnotetext{
11 We prefer an assets index to total household expenditure since the latter is constructed from only six broad categories of expenditures (food, housing and utilities, education, health care, insurance premiums, and all other goods and services) and yields rather low estimates of household spending (Xu et al., 2009). Results were qualitatively similar when using household expenditures instead of a wealth index and can be obtained from the authors upon request.
} 
derived from factor analysis on the entire set of need variables, with the ten wealth-urban groups fully interacted with this index (see Table 2). The other non-need variables listed in Table 1 are also included. ${ }^{12}$ In all groups, except for three of the rural wealth quintiles for inpatient care, health care use responds positively to need, but it generally does so to a greater extent in higher wealth quintiles and in urban locations. For both any care and inpatient care, the relationship is strongest in the urban part of the upper wealth quintile. The joint test of no interactions of group dummies and bealthfactor rejects the null of equality of coefficients for any care $(\mathrm{p}=0.01)$, but not for inpatient care $(\mathrm{p}=0.45)$. Even in the latter case, the marginal effect of need on the probability of an inpatient visit rises from effectively zero for those in the highest wealth quintile living in rural areas to 0.08 for urban dwellers in the same wealth group. Within urban areas, the probability of an inpatient stay rises from 0.05 in the lowest quintile to 0.08 in the highest. These results confirm that in the Philippines, and conditional on self-reported health problems, people with higher capacity to pay and living in more urban areas are more likely to seek care. It seems unlikely that there is much discretionary, unnecessary care in the Philippines even in the higher upper wealth quintile - and so the stronger use-need relationship among the urban part of the richest wealth quintile is likely to reflect a medically more appropriate treatment response to need. Under this assumption, we take the use-need relationship of the highest urban wealth group as the reference against which to measure equity.

\section{Decomposition of socioeconomic inequality in utilisation}

The results of the decomposition (equation 7) are displayed in Table 3- the left panel for any care and the right panel for inpatient care. The full regression results for the 10 wealthurban/rural subgroups and the pooled sample on which the decomposition is based can be found in Appendix Tables 2 and 3 for any care and inpatient care respectively. In the decomposition, we use the full set of need variables, not the composite needs index. The first column of each panel in Table 3 gives the first (need variables) and fourth (non-need variables) terms in equation (7) - the contribution of each factor to wealth-related inequality in health care use under the assumption of homogeneous effects. This corresponds to the standard concentration index decomposition (Wagstaff et al., 2003). For need variables, the second and third column within each panel give the contribution

\footnotetext{
12 The variable bealthfactor combines information on all the need variables, and is increasing in ill-health. The demographics and child1y are not included in the factor analysis, because, although related to health care need, they do not reflect ill-health status as do the other need-related variables. Factor loadings were found to have intuitive signs and can be obtained from the authors upon request.
} 
arising from heterogeneity in the use-need relationship separated into the corrected need effect (term 2 in (7)) and discrimination (term 3 in (7)). For the non-need variables, the lower half of the third column gives contributions from the heterogeneous effects of the non-need variables on health care use. The third from final row of the table gives the contribution of the wealth-urban/rural specific intercepts (term 6 in (7)), while the second from bottom row gives that of the residual correlation of health care with wealth rank (term 7).

It is clear that the largest contribution to SES inequality in both types of health care use derives from the direct effect of the wealth and urbanicity dummies (0.059). This indicates that poorer people mainly use less care because they face greater financial and geographical barriers. With respect to the homogenous contributions, for a variable to contribute positively to explaining the wealth-related concentration index of 0.083 for any care, it must be positively correlated with both wealth (positive concentration index in Table 1) and the probability of using any health care (first column in Appendix Table 2). In total, these contributions are positive for non-need variables (0.026), with the largest part due to education (0.02). The occupational variables contribute little (0.01). The need variables contribute negatively to SES inequality in health care use (-0.034). This is because ill health conditions are generally predictive of health care use, and more concentrated among the poor. All else equal, the distribution of the need variables would lead to a pro-poor distribution of health care use. If horizontal equity were satisfied, inequalities in health care use would only result from differences in the need for health care. The part of inequality that derives from non-need variables is considered inequitable. The conventional horizontal inequity index, calculated as the concentration index minus the contributions from need variables under the assumption of homogeneous effects (equation 4), equals 0.12 , suggesting that measured inequity, which takes account of the greater concentration of need among the poor, is greater than measured inequality in the distribution of any health care.

The sum of the need contributions in the second column (corrected need) is also negative (-0.012), indicating that need justified inequality is underestimated if predicted on the basis of the use-need relationship holding in the pooled sample, rather than that in the urban wealthiest quintile. Need justified inequality as a percentage of the concentration index for any care rises from $42 \%$ to $56 \%$ when the vertical equity norm is taken from the reference group. As a result, the adjusted inequity index $I_{2}=0.13$ is greater than that of $I_{1}=0.12$. 
In total, the discrimination effect of the need variables contributes 0.04 to the prorich inequality in health care use. That is, almost half of the observed socioeconomic inequality in use is due to utilisation being more responsive to need among the higher wealth and urban dwelling individuals. The pro-rich discrimination is most evident in the treatment of oral problems (0.017), bad self-assessed health (0.015) and child bearing (0.014). The heterogeneous effects of the non-need variables are contributing much less (0.001) to SES related inequality in any health care use, which is due to offsetting effects of education and occupational status.

The right panel of Table 3 shows the decomposition results for the use of inpatient care. In general, decomposition results are very similar to those for inequality in the use of any care. The total corrected need effect is again negative and larger as compared to any care (-0.02 compared to -0.01), indicating that the need justified inequality in inpatient care in favour of the poor is underestimated when the pooled use-need relationship is used, rather than the relationship holding among high wealth urban dwellers. The Inequity Index increases from 0.08 to 0.1 when using the urban $Q^{5}$ relationship between need and use as the vertical equity norm instead of the average population relationship.

\section{Analogy with Blinder-Oaxaca decomposition}

As discussed before, there is a clear analogy between the decomposition in (7) and the Blinder-Oaxaca decomposition (Blinder, 1973; Oaxaca, 1973). In the latter, the homogeneous contributions, the corrected need effect and the direct urban/wealth effects in Table 3 correspond to the contribution of endowments. Note that the sum of the homogeneous need contributions and the corrected need effect represents the extent to which differences in the distribution of need contribute to SES inequality in the use of health care, using the coefficients from the upper wealth and urban group as the reference values. ${ }^{13}$ The contribution of the heterogeneous effects of the need (as compared to urban Q5) and non-need coefficients (as compared to pooled values) to SES inequality in health care use are conceptually similar to the coefficients' contribution in Blinder-Oaxaca. Figure 1 presents the decomposition results along these lines and clearly illustrates that pro-rich inequality in both types of health care use is driven to a large extent by differences in the distribution of non-need related variables (including

\footnotetext{
${ }^{13}$ Several weighting alternatives have been suggested in the decomposition literature (see e.g. Neumark, 1988; Oaxaca and Ransom, 1994).
} 
wealth/urban). Slightly less than half of all pro-rich inequality is related to the heterogeneous responsiveness of health care use to need and non-need variables.

Compared to the standard decomposition with homogenous effects in the left panel of the graph, the new decomposition adds two elements: (i) the contributions of need and non-need variables arising from allowing for heterogeneity in coefficients, and (ii) the corrected need contribution deriving from the adoption of a different vertical norm. The heterogeneity contribution of the need variables also reveals the discrimination, or socioeconomic-related vertical inequity, that was hidden under the standard assumption.

\section{Comparison with three other Asian countries}

In order to examine how typical the results for the Philippines are, we have applied the same decomposition to three other Asian countries: Bangladesh, India, and Malaysia with sufficiently large WHS sample sizes (i.e. $\mathrm{n}>5000$ ) to allow for an analysis of heterogeneity. As these sample sizes are still much smaller than for the Philippines, we could only allow for heterogeneity in coefficients across six urban/rural wealth tertiles (instead of quintiles). We take the need-use relationship from the urban and upper wealth tertile to be the reference ${ }^{14}$. The summary decomposition results are presented in Figures 2 and 3. For the use of any care, all adjustments work in the same direction and confirm the expected increase in pro-rich inequity. The country ranking is unaffected: India shows greatest pro-rich inequality, with or without need adjustment, and with or without allowance for heterogeneity. For inpatient use, we find similar results. Socioeconomic inequality is smallest, even pro-poor, in Malaysia. This squares with findings from an earlier cross-country comparison using much larger surveys which found that Malaysia managed to obtain a much more equal or even pro-poor distribution of its public subsidy to health care than India or Bangladesh (O'Donnell et al., 2007). The need correction works again in the expected direction and increases the degree of pro-rich inequity, confirming the limitation of relying on the average relationship to provide the vertical equity norm. Another noteworthy observation is that the contribution of the "heterogeneity in coefficients" (for both need and non-need variables) can be negative.

This suggests that in some cases the combination of unequal distributions of endowments and coefficients can have a pro-poor influence. In all three countries, the discrimination effect for any care is negative, which means that the different responsiveness

\footnotetext{
${ }^{14}$ The coefficient on the ill health factor in the upper wealth tertile is greater than that in the pooled sample in all countries, both for any care and inpatient care.
} 
of the health care system to the needs of any subgroup, as compared to the reference group, contributes to socioeconomic inequality favouring the poor. This can be a result of use being less responsive to need in the reference group, and/or need being more concentrated in the higher SES groups. In Malaysia for example, the demographics are responsible for the negative discrimination effect as older women are more concentrated among the rich and are more likely to seek care in the poorer/rural thirds as compared to the upper wealth \& urban third (reference).

Figure 3 shows corrected concentration and inequity indices under the assumption of homogeneous $\left(I_{1}\right.$ from (4)) and heterogeneous effects $\left(I_{2}\right.$ from (8)) panel A for any care and B for inpatient care. For all three countries, inequity in both types of care is larger than inequality and adopting the urban upper wealth coefficients as the vertical equity norm further increases the measured degree of inequity. In general, the heterogeneity adjustment is somewhat more important for inequity in inpatient care than in any care. Together with the results for the Philippines, these results confirm that not taking into account heterogeneity of the use-need relationship causes inequity in health care delivery to be underestimated.

\section{Conclusion}

This paper presents a method of allowing for heterogeneity in the use-need relationship while measuring and decomposing inequity in health care utilisation. The decomposition makes explicit inequity that derives from unequal response to variation in need, as well as that due to differential effects of non-need determinants. If the use is more responsive to need among the rich and need is concentrated among the poor, then existing methods that impose homogeneity will underestimate pro-rich inequity. This prediction is confirmed for four low-middle income Asian countries.

While the proposed method has distinct advantages over previous measures of inequity in health care utilisation, it is not without its limitations. Some of these are common to previous measures. For example, there may be bias from measurement error in need (Bago d'Uva et al., 2011) and inequality in the quality of care is ignored (Jones et al., 2011). As with previous decompositions of the concentration index, the method only holds for linear estimators. Abandoning linearity can only be achieved at the cost of losing the exact decomposition of the inequality index into additive components and introducing approximation errors (Huber, 2008; Van Doorslaer et al., 2004) 
Specific to the proposed method, a normative choice has to be made of the population group presumed to come closest to receiving the appropriate treatment response to need. The appropriate choice will be context specific. If the analysis concerns inequity in treatment of a specific condition for which there is a narrow and specific measure of need, then there may exist a medically appropriate treatment response to need. But most analyses are conducted at a much more general level with a broad measure of health care utilisation and a generic need indicator, or a battery of need measures. In this case, there is no externally defined vertical equity norm in the use-need relationship to call on and one must look within the data. In the application presented here, we chose the relationship holding for the group least likely to confront financial and geographic barriers to health care - the richest wealth quintile living in urban areas. In other contexts, the group with the most comprehensive health insurance coverage, e.g. civil servants in low-income countries, might be taken as the reference. When multiple need indicators are used, as in our application, it is likely that the use-need relationship will not be consistently strongest in the reference group. This can result in discrimination effects contributing to inequity in favour of the poor.

Implicitly, we have presumed that the vertically equitable use-need relationship is defined on the basis of medical effectiveness rather than economic efficiency. In predicting legitimate, i.e. needs-based, variation in utilisation on the basis of the use-need relationship holding for a privileged population, the resource constraint is ignored. Total predicted utilisation will exceed total actual utilisation. Applying the average use-need relationship, as has previously been done, ensures that the total remains constant. The previous measure addresses the question of whether the existing amount of health care is equitably distributed. Our proposed approach simply asks whether health care is equitably distributed. It can be criticized for measuring inequity against a counterfactual that is not feasible without a substantial increase in health care resources sufficient for all to be treated as the most privileged. This is a valid criticism. But addressing it would mean once again understating the inequity arising from the unequal distribution of need and the socioeconomic bias in the response to need. Take the situation in which need is heavily concentrated among the poor but only the richest person in need gets treatment. The average use-need relationship will be weak - near zero. Using this, the legitimate inequality in favour of the poor will be grossly understated. Inequity will still be identified but only through the deviation of the observed unequal distribution of utilisation from an equal distribution. Our approach will identify inequity as the deviation of the observed distribution from one that favours the poor as a result of their greater need established 
from the treatment response that is achievable when resources permit. To an extent, this recognises two levels of inequity - that against the poor and that against a poor country. 


\section{Tables \& Figures}

\begin{tabular}{|c|c|c|c|c|c|}
\hline & Variable & Description & Mean & $\mathrm{CC}$ & $\mathrm{SD}$ \\
\hline \multirow{27}{*}{ 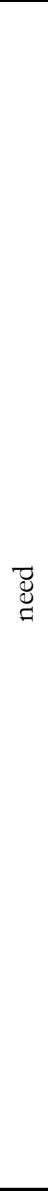 } & daily & severe/ extreme problems with performing daily activities in last 30 days & 0.03 & -0.02 & 0.05 \\
\hline & vigorous & severe/extreme problems with performing vigorous activities in last 30 & 0.10 & -0.04 & 0.03 \\
\hline & selfcare & severe/extreme problems with taking care of his/herself in last 30 days & 0.02 & -0.01 & 0.06 \\
\hline & pain & severe/extreme pain or bodily discom fort in last 30 days & 0.06 & -0.05 & 0.04 \\
\hline & cognition & severe/ extreme difficulty with concentrating/remembering things in last & 0.04 & -0.03 & 0.04 \\
\hline & relation & $\begin{array}{l}\text { severe/extreme problems in personal relationships, participation in the } \\
\text { communities, or dealing with tensions and conflicts in the last } 30 \text { days }\end{array}$ & 0.03 & -0.02 & 0.05 \\
\hline & seeing & $\begin{array}{l}\text { severe/ extreme problems in seeing and recognizing a person across the } \\
\text { road or an object at an arm's length in the last } 30 \text { says }\end{array}$ & 0.08 & -0.04 & 0.03 \\
\hline & sleep & severe/extreme problems with sleeping or feeling rested in the last 30 days & 0.07 & -0.02 & 0.03 \\
\hline & badhealth & self assessed health moderate, bad or very bad & 0.42 & -0.08 & 0.01 \\
\hline & arthritis & experienced symptoms of arthritis in last 12 months & 0.11 & -0.01 & 0.03 \\
\hline & badk & back pain in the last 30 days & 0.40 & -0.11 & 0.01 \\
\hline & angina & experienced symptoms of angina in last 12 months & 0.15 & -0.06 & 0.01 \\
\hline & asthma & experienced symptoms of asthma in last 12 months & 0.08 & -0.05 & 0.02 \\
\hline & depression & experienced symptoms of depression in last 12 months & 0.02 & -0.02 & 0.03 \\
\hline & psychosis & experienced symptoms of psychosis in last 12 months & 0.04 & -0.02 & 0.05 \\
\hline & TB & experienced symptoms of tuberculosis in last 12 months & 0.02 & -0.01 & 0.05 \\
\hline & dhild1y & had delivery in last year & 0.05 & -0.03 & 0.03 \\
\hline & child5y & had delivered in the last 5 years & 0.17 & -0.06 & 0.01 \\
\hline & accident & involved in accident or bodily injury in last 12 months & 0.05 & -0.01 & 0.03 \\
\hline & oralprob & had any problems with mouth or teeth during the last 12 months & 0.38 & -0.09 & 0.01 \\
\hline & difhh & moderate/severe/extreme problems with work or household activities & 0.51 & -0.12 & 0.01 \\
\hline & $\underline{\mathrm{F} 18-30}$ & female, aged $18-30$ years & 0.16 & 0.02 & 0.01 \\
\hline & F30-50 & female, aged $30-50$ years & 0.23 & -0.01 & 0.01 \\
\hline & F50plus & female, older than 50 years & 0.13 & 0.04 & 0.01 \\
\hline & M18-30 & male, aged $18-30$ years & 0.17 & 0.00 & 0.01 \\
\hline & M30-50 & male, aged $30-50$ years & 0.20 & -0.05 & 0.01 \\
\hline & M50plus & male, older than 50 years & 0.10 & 0.00 & 0.01 \\
\hline \multirow{10}{*}{$\begin{array}{l}\vec{Z} \\
\mathbb{Z} \\
\mathbb{1} \\
\tilde{E} \\
0\end{array}$} & married & aurrently married or cohabitating & 0.69 & -0.11 & 0.01 \\
\hline & noeduc & no formal schooling or less than primary & 0.19 & -0.30 & 0.02 \\
\hline & primeduc & primary education & 0.30 & -0.19 & 0.02 \\
\hline & seceduc & secondary education & 0.34 & 0.20 & 0.01 \\
\hline & higheduc & higher than secondary education & 0.17 & 0.29 & 0.02 \\
\hline & govemp & government employee & 0.06 & 0.07 & 0.01 \\
\hline & nongovemp & non-government employee & 0.14 & 0.06 & 0.01 \\
\hline & selfemp & self employed & 0.29 & -0.13 & 0.02 \\
\hline & epml & eployer & 0.04 & -0.04 & 0.01 \\
\hline & notwork & not working & 0.47 & 0.03 & 0.02 \\
\hline \multirow{10}{*}{ 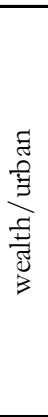 } & urban \& Q5 & household is in upper wealth quintile \& urban & 0.16 & 0.51 & 0.03 \\
\hline & urban \& Q4 & household is in second upperwealth quintile \& urban & 0.13 & 0.18 & 0.01 \\
\hline & urban \& Q3 & household is in middle wealth quintile \& urban & 0.11 & -0.03 & 0.01 \\
\hline & urban \& Q2 & household is in 2nd lowest wealth quintile \& urban & 0.08 & -0.13 & 0.01 \\
\hline & urban \& Q1 & household is in lowest wealth quintile \& urban & 0.04 & -0.14 & 0.02 \\
\hline & rural \& Q5 & household is in upper wealth quintile \& rural & 0.06 & 0.20 & 0.03 \\
\hline & rural \& Q4 & household is in second upperwealth quintile \& rural & 0.08 & 0.10 & 0.01 \\
\hline & rural \& Q3 & household is in middle wealth quintile \& rural & 0.08 & -0.02 & 0.01 \\
\hline & rural \& Q2 & household is in 2nd lowest wealth quintile \& rural & 0.11 & -0.20 & 0.01 \\
\hline & rural \& Q1 & household is in lowest wealth quintile \& rural & 0.15 & -0.48 & 0.03 \\
\hline
\end{tabular}

Table 1: Description of variables, their means and corrected concentration indices (CC) - the Philippines. Source: Authors' calculations from the Philippines World Health Survey.

Notes: Concentration indices describe inequality of each variable in relation to rank in the distribution of the wealth index. SE - standard error of CC. Underscored variables are used as reference categories in regression models. 


\begin{tabular}{|c|c|c|c|c|c|c|c|c|c|c|c|}
\hline \multicolumn{12}{|c|}{ any care in last year } \\
\hline & pooled & $\begin{array}{c}\text { urban \& } \\
\text { Q5 }\end{array}$ & $\begin{array}{c}\text { urban \& } \\
\text { Q4 }\end{array}$ & $\begin{array}{c}\text { urban \& } \\
\text { Q3 }\end{array}$ & $\begin{array}{c}\text { urban \& } \\
\text { Q2 }\end{array}$ & $\begin{array}{c}\text { urban \& } \\
\text { Q1 }\end{array}$ & $\begin{array}{l}\text { rural } \\
\& \text { Q5 }\end{array}$ & $\begin{array}{l}\text { rural } \\
\& \text { Q4 }\end{array}$ & $\begin{array}{c}\text { rural \& } \\
\text { Q3 }\end{array}$ & $\begin{array}{c}\text { rural \& } \\
\text { Q2 }\end{array}$ & $\begin{array}{c}\text { rural \& } \\
\text { Q1 }\end{array}$ \\
\hline $\begin{array}{l}\text { ill health- } \\
\text { factor }\end{array}$ & $0.089 * * *$ & $0.138^{* * *}$ & $0.122 * * *$ & $0.087 * * *$ & $0.110 * * *$ & $0.055^{* *}$ & $0.067^{*}$ & $0.049 *$ & $0.117 * * *$ & $0.091 * * *$ & $0.053 * * *$ \\
\hline \multicolumn{12}{|c|}{ inpatient care in last 5 years } \\
\hline & pooled & $\begin{array}{c}\text { urban \& } \\
\text { Q5 }\end{array}$ & $\begin{array}{c}\text { urban \& } \\
\text { Q4 }\end{array}$ & $\begin{array}{c}\text { urban \& } \\
\text { Q3 }\end{array}$ & $\begin{array}{c}\text { urban \& } \\
\text { Q2 }\end{array}$ & $\begin{array}{c}\text { urban \& } \\
\text { Q1 }\end{array}$ & $\begin{array}{l}\text { rural } \\
\& \text { Q5 }\end{array}$ & $\begin{array}{l}\text { rural } \\
\& \text { Q4 }\end{array}$ & $\begin{array}{c}\text { rural \& } \\
\text { Q3 }\end{array}$ & $\begin{array}{c}\text { rural \& } \\
\text { Q2 }\end{array}$ & $\begin{array}{c}\text { rural \& } \\
\text { Q1 }\end{array}$ \\
\hline $\begin{array}{l}\text { ill health- } \\
\text { factor }\end{array}$ & $0.050 * * *$ & $0.081 * * *$ & $0.036^{*}$ & $0.073 * * *$ & $0.045^{* *}$ & $0.051 * * *$ & 0.005 & 0.025 & $0.069 * *$ & $0.031 *$ & $0.052^{* * *}$ \\
\hline Observations & 9472 & 1472 & 1361 & 1260 & 963 & 559 & 439 & 568 & 643 & 908 & 1271 \\
\hline
\end{tabular}

Table 2: Coefficients of ill health-factor in linear probability models of using any care and inpatient care by subgroups - the Philippines.

Notes: ill health-factor is the first factor from factor analysis on the set of need related variables in Table 1 (excluding demographics and the variable child1y). Models also include all non-need related variables as indicated in Table $1 . * * *, * *, *$ indicates significant at $1 \%, 5 \%, 10 \%$. 


\begin{tabular}{|c|c|c|c|c|c|c|}
\hline & \multicolumn{3}{|c|}{ any care in last year } & \multicolumn{3}{|c|}{ inpatient care in last 5 years } \\
\hline & homogeneous & $\begin{array}{c}\text { corrected } \\
\text { need }\end{array}$ & heterogeneous & homogeneous & $\begin{array}{c}\text { corrected } \\
\text { need }\end{array}$ & heterogeneous \\
\hline \multicolumn{7}{|l|}{ need } \\
\hline daily & -0.0004 & -0.0034 & 0.0079 & -0.0012 & 0.0012 & -0.0066 \\
\hline vigorous & -0.0019 & 0.0029 & -0.0040 & -0.0022 & 0.0006 & 0.0046 \\
\hline selfcare & -0.0005 & 0.0000 & 0.0022 & -0.0005 & 0.0028 & -0.0015 \\
\hline pain & -0.0027 & 0.0028 & -0.0073 & -0.0024 & -0.0053 & 0.0064 \\
\hline cognition & 0.0017 & 0.0013 & -0.0085 & 0.0017 & -0.0003 & 0.0011 \\
\hline relation & 0.0005 & -0.0005 & 0.0008 & -0.0008 & 0.0004 & -0.0020 \\
\hline seeing & 0.0008 & -0.0057 & 0.0088 & -0.0002 & -0.0066 & 0.0107 \\
\hline sleep & -0.0009 & 0.0009 & 0.0009 & -0.0002 & 0.0011 & -0.0010 \\
\hline badhealth & -0.0039 & -0.0024 & 0.0147 & -0.0016 & -0.0023 & -0.0003 \\
\hline arthritis & -0.0003 & 0.0005 & -0.0036 & -0.0002 & 0.0000 & 0.0025 \\
\hline back & -0.0017 & -0.0063 & 0.0075 & 0.0000 & -0.0007 & -0.0095 \\
\hline angina & -0.0028 & -0.0022 & 0.0125 & -0.0004 & -0.0008 & 0.0129 \\
\hline asthma & -0.0026 & 0.0000 & -0.0010 & -0.0030 & -0.0034 & 0.0071 \\
\hline depression & -0.0023 & 0.0004 & -0.0003 & -0.0024 & -0.0007 & 0.0029 \\
\hline paranoia & -0.0004 & 0.0012 & -0.0022 & -0.0001 & 0.0019 & -0.0062 \\
\hline TB & -0.0016 & -0.0005 & 0.0022 & -0.0009 & -0.0008 & 0.0026 \\
\hline oralprob & -0.0071 & -0.0037 & 0.0173 & 0.0005 & -0.0003 & -0.0100 \\
\hline accident & -0.0030 & -0.0008 & 0.0064 & -0.0010 & -0.0012 & 0.0063 \\
\hline childy & -0.0074 & -0.0025 & 0.0139 & -0.0109 & -0.0084 & 0.0420 \\
\hline diffhh & -0.0021 & 0.0001 & -0.0002 & 0.0004 & 0.0011 & -0.0064 \\
\hline F30-50 & -0.0001 & 0.0010 & -0.0127 & 0.0000 & 0.0001 & -0.0025 \\
\hline F50plus & 0.0020 & 0.0006 & 0.0015 & 0.0010 & 0.0000 & -0.0034 \\
\hline M18-30 & -0.0001 & 0.0000 & -0.0031 & -0.0001 & -0.0001 & -0.0013 \\
\hline M30-50 & 0.0023 & 0.0039 & -0.0158 & -0.0001 & 0.0016 & -0.0156 \\
\hline M50plus & 0.0001 & 0.0000 & 0.0021 & 0.0001 & 0.0000 & -0.0008 \\
\hline total need & -0.0343 & -0.0125 & 0.0400 & -0.0242 & -0.0203 & 0.0320 \\
\hline \multicolumn{7}{|l|}{ non-need } \\
\hline married & -0.0025 & & 0.0216 & -0.0020 & & 0.0395 \\
\hline primeduc & -0.0079 & & 0.0107 & -0.0006 & & -0.0152 \\
\hline seceduc & 0.0136 & & 0.0215 & 0.0030 & & -0.0026 \\
\hline higheduc & 0.0144 & & 0.0204 & 0.0135 & & 0.0044 \\
\hline govemp & -0.0046 & & -0.0142 & -0.0026 & & -0.0033 \\
\hline nongovemp & 0.0113 & & -0.0145 & 0.0049 & & -0.0056 \\
\hline selfemp & 0.0038 & & -0.0040 & 0.0018 & & 0.0019 \\
\hline epml & -0.0024 & & -0.0406 & -0.0005 & & -0.0131 \\
\hline total non-need & 0.0258 & & 0.0010 & 0.0175 & & 0.0061 \\
\hline wealth/urban & 0.0588 & & & 0.0440 & & \\
\hline error & 0.0041 & & & 0.0039 & & \\
\hline Total & 0.0830 & & & 0.0590 & & \\
\hline
\end{tabular}

Table 3: Decomposition of concentration index for use of any care and inpatient care as in equation (7) - the Philippines

Notes: Homogenous refers to term (1) and (4) for need \& non-need related variables respectively. Corrected need refers to term (2). Heterogeneous relates to term (3) and (5) for need \& non-need related variables respectively. 


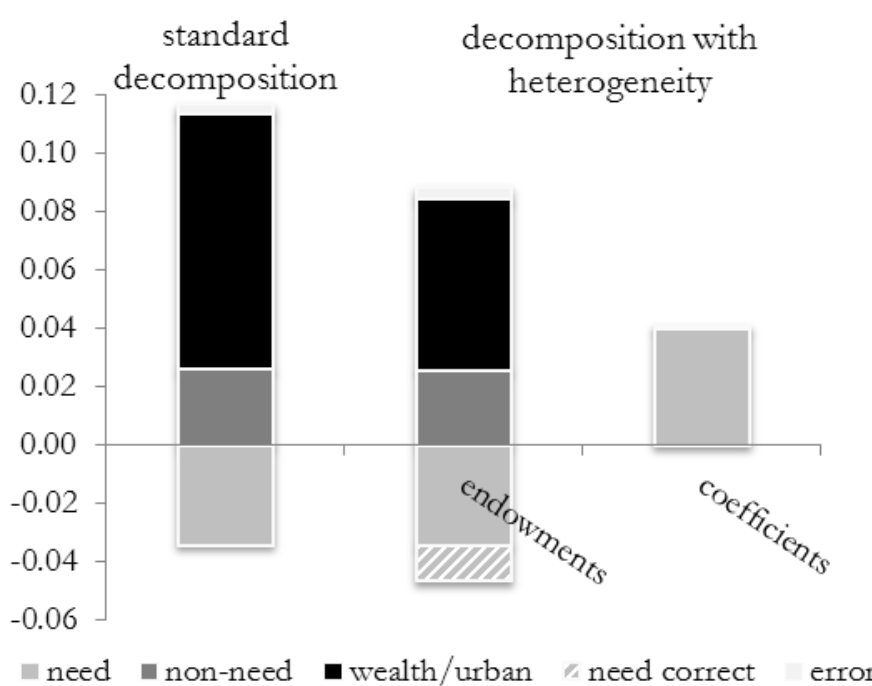

A. Any care

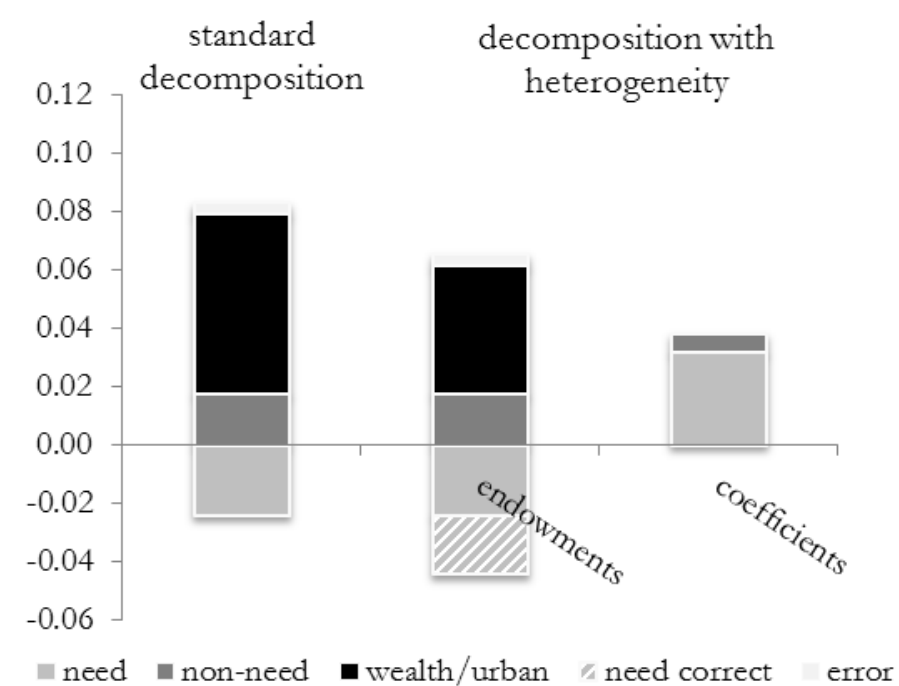

B. Inpatient care

Figure 1: Standard and expanded decomposition of concentration index for any $\&$ inpatient care for the Philippines. 


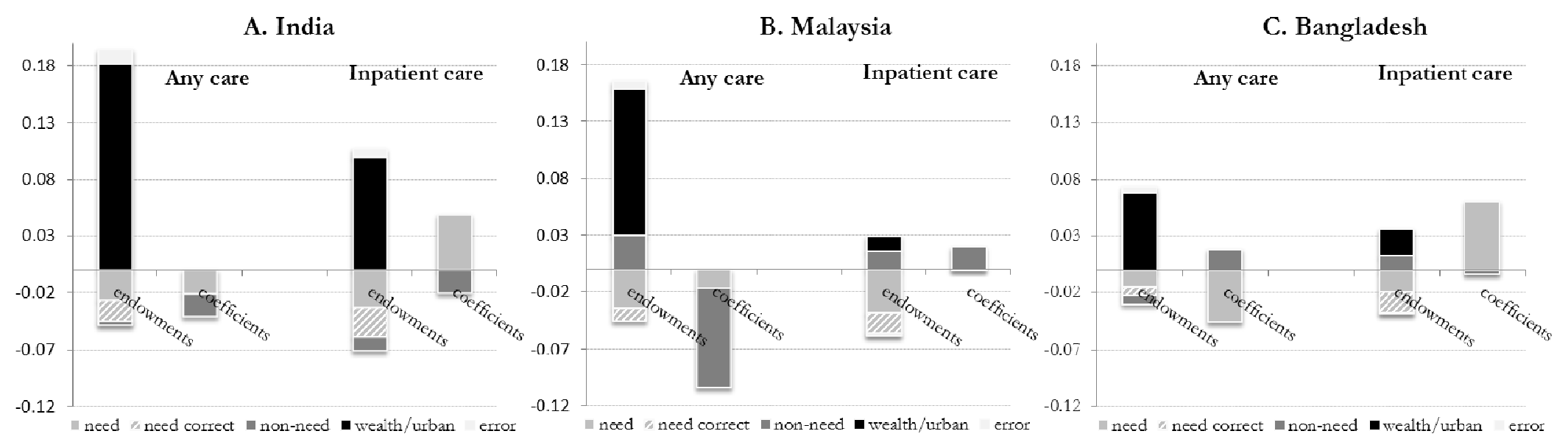

Figure 2: Expanded decomposition of concentration index for any \& inpatient care for India (A), Malaysia (B) and Bangladesh (C). 

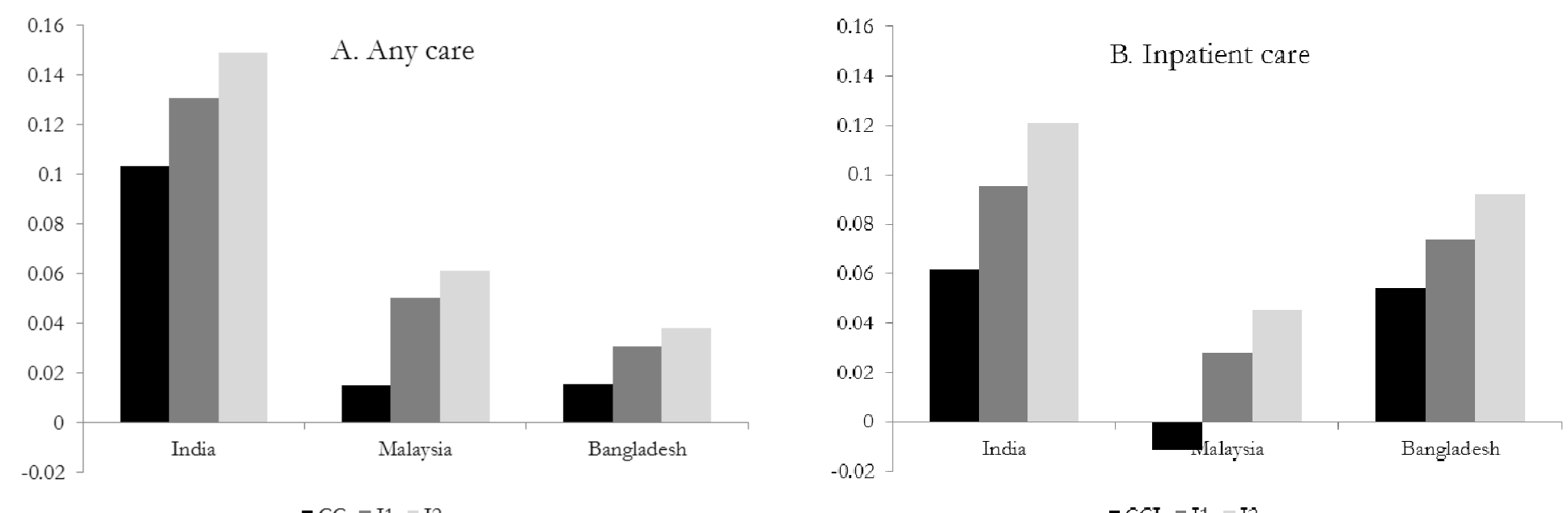

Figure 3: Concentration and inequity indices in any care (A) and inpatient care (B) for India, Malaysia \& Bangladesh.

Notes: CC is Erreygers' corrected concentration index. I1 is inequity index by equation (4). I2 is inequity index by equation (8). 
Appendix 1: Decomposition of the Erreygers' Corrected Concentration Index

The conventional approach

$C C_{y}=8 \operatorname{cov}\left(y_{i}, R_{i}\right)$

$y_{i}=\alpha^{P}+\sum_{j=1}^{J} \beta_{j}^{P} x_{j i}+\sum_{k=1}^{K} \gamma_{k}^{P} z_{k i}+\sum_{g=2}^{G} \delta_{g}^{P} D_{g i}+\varepsilon_{i}$

$C C_{y}=4\left[\sum_{j=1}^{J} \beta_{j}^{P} \bar{x}_{j} C_{x_{j}}+\sum_{k=1}^{K} \gamma_{k}^{P} \bar{z}_{k} C_{z_{k}}+\sum_{g=2}^{G} \delta_{g}^{P} \bar{D}_{g} C_{D_{g}}+G C_{\varepsilon}\right]$

$I_{1}=C C_{y}-4 \sum \beta_{j}^{P} \bar{x}_{j} C_{x_{j}} \quad$,

Measuring inequity with heterogeneous effects

$$
\begin{aligned}
y_{i}= & \alpha_{g}+\sum_{j=1}^{J} \beta_{j g} x_{j i}+\sum_{k=1}^{K} \gamma_{k g} z_{k i}+u_{i}, \quad i \in g, \quad g=1, \ldots . G \\
C C_{y}= & 4 \sum_{j} \beta_{j}^{P} \bar{x}_{j} C_{j}+\frac{8}{N} \sum_{j} \sum_{i} x_{j i}\left(\beta_{j g}-\beta_{j}^{P}\right)\left(R_{i}-1 / 2\right)+ \\
& 4 \sum_{k} \gamma_{k}^{P} \bar{z}_{k} C_{k}+\frac{8}{N} \sum_{k} \sum_{i} z_{k i}\left(\gamma_{k g}-\gamma_{k}^{P}\right)\left(R_{i}-1 / 2\right)+ \\
& 8 \operatorname{cov}\left(\alpha_{g}, R_{i}\right)+8 \operatorname{cov}\left(u_{i}, R_{i}\right)
\end{aligned}
$$

$$
\begin{aligned}
C C_{y}= & \overbrace{4 \sum_{j} \beta_{j}^{P} \bar{x}_{j} C_{j}}^{1=\text { homogeneous need }}+\overbrace{\frac{8}{N} \sum_{j}\left(\beta_{j g_{r}}-\beta_{j}^{P}\right) \sum_{i} x_{i j}\left(R_{i}-1 / 2\right)}^{\text {=corrected need }}+ \\
& \overbrace{\frac{8}{N} \sum_{j} \sum_{i} x_{j i}\left(\beta_{j g}-\beta_{j g_{r}}\right)\left(R_{i}-1 / 2\right)}^{3=\text { discrimination }}+\overbrace{4 \sum_{k} \gamma_{k}^{P} \bar{z}_{k} C_{k}}^{4=\text { homogeneous non-need }}+ \\
& \overbrace{\frac{8}{N} \sum_{k} \sum_{i} z_{k i}\left(\gamma_{k g}-\gamma_{k}^{P}\right)\left(R_{i}-1 / 2\right)}^{\text {heterogeneity in non-need effects }}+ \\
& \overbrace{8 \operatorname{cov}\left(\alpha_{g}, R_{i}\right)}^{6=\mathrm{G} \text { subgroups }}+\overbrace{8 \operatorname{cov}\left(u_{i}, R_{i}\right)}^{7=\text { error contribution }}
\end{aligned}
$$$$
I_{2}=C C_{y}-4 \sum_{j} \beta_{j}^{P} \bar{x}_{j} C_{j}-\frac{8}{N} \sum_{j}\left(\beta_{j g_{r}}-\beta_{j}^{P}\right) \sum_{i} x_{i j}\left(R_{i}-1 / 2\right)
$$$$
=\mathrm{CC}_{y}-4 \sum_{j} \beta_{j g_{r}} \bar{x}_{j} C_{j}
$$ 


\begin{tabular}{|c|c|c|c|c|c|c|c|c|c|c|c|}
\hline & \multicolumn{11}{|c|}{ any care in last year } \\
\hline & pooled & urban \& Q5 & urban \& Q4 & urban \& Q & 3 urban \& Q2 & urban \& Q1 & rural \& Q5 & rural \& Q4 & rural \& Q3 & rural \& Q2 & rural \& Q1 \\
\hline daily & 0.025 & $0.228^{* * *}$ & 0.149 & 0.113 & 0.162 & 0.072 & $0.362^{* *}$ & -0.153 & -0.164 & 0.125 & -0.119 \\
\hline vigourous & $0.047^{*}$ & -0.025 & 0.039 & 0.018 & 0.094 & 0.024 & 0.047 & 0.033 & $0.238^{* *}$ & -0.005 & 0.022 \\
\hline selfcare & 0.041 & 0.038 & 0.11 & 0.005 & 0.199 & 0.117 & -0.164 & 0.147 & $0.489 * * *$ & $-0.252^{* *}$ & -0.102 \\
\hline pain & $0.057^{*}$ & 0.002 & 0.104 & 0.103 & -0.077 & 0.021 & -0.137 & 0.158 & -0.056 & 0.089 & $0.129 * *$ \\
\hline cognition & $-0.051^{*}$ & -0.088 & $-0.318^{* * *}$ & -0.044 & $-0.212 * * *$ & -0.073 & $-0.276^{* *}$ & -0.065 & -0.065 & $0.146^{*}$ & 0.02 \\
\hline relation & -0.03 & 0.005 & 0.033 & -0.179 & $0.161 *$ & -0.083 & 0.013 & $-0.211^{*}$ & -0.001 & -0.147 & -0.03 \\
\hline seeing & -0.022 & $0.139 * *$ & 0.007 & 0.002 & -0.064 & -0.019 & $-0.191 * *$ & -0.152 & 0.023 & 0.068 & $-0.101 * *$ \\
\hline sleep & 0.036 & -0.002 & $0.224 * * *$ & -0.017 & 0.017 & -0.139 & 0.014 & 0.094 & -0.036 & 0.061 & 0.063 \\
\hline badhealth & $0.050^{* * *}$ & $0.080 * *$ & $0.080^{* *}$ & 0.025 & $0.084 * *$ & $0.082^{*}$ & 0.056 & 0.002 & 0.035 & 0.008 & 0.023 \\
\hline arthritis & $0.039 *$ & -0.017 & -0.004 & $0.102 * *$ & 0.086 & 0.047 & 0.069 & 0.03 & 0.042 & 0.058 & 0.018 \\
\hline back & 0.015 & $0.071^{*}$ & -0.034 & -0.006 & 0.053 & 0.034 & -0.036 & -0.041 & 0.022 & $0.077^{*}$ & -0.026 \\
\hline angina & $0.048^{* *}$ & $0.078^{*}$ & 0.012 & 0.06 & 0.061 & -0.006 & $0.141^{*}$ & 0.099 & 0.07 & -0.025 & 0.021 \\
\hline asthma & $0.058^{* *}$ & 0.044 & 0.092 & 0.037 & 0.076 & 0.077 & 0.028 & 0.028 & $0.184^{* *}$ & -0.057 & 0.099 \\
\hline depression & $0.153^{* * *}$ & 0.134 & 0.105 & -0.005 & 0.155 & $0.208^{*}$ & 0.264 & 0.206 & $0.368^{* *}$ & 0.108 & 0.119 \\
\hline paranoia & 0.019 & -0.041 & -0.076 & 0.061 & 0.009 & -0.028 & $0.287^{* *}$ & 0.103 & -0.024 & 0.076 & 0.053 \\
\hline $\mathrm{TB}$ & $0.143^{* * *}$ & $0.198^{*}$ & -0.067 & 0.156 & 0.077 & 0.081 & 0.065 & $0.561 * * *$ & 0.024 & $0.357^{* *}$ & 0.054 \\
\hline oralprob & $0.083^{* * *}$ & $0.125^{* * *}$ & $0.121 * * *$ & $0.090 * * *$ & $0.093^{* *}$ & $0.082^{*}$ & 0.062 & 0.052 & 0.04 & $0.082^{* *}$ & 0.049 \\
\hline accident & $0.206^{* * *}$ & $0.264^{* * *}$ & $0.285^{* * *}$ & $0.250^{* * *}$ & $0.197 * * *$ & $0.195^{* *}$ & 0.218 & $0.349^{* * *} *$ & 0.123 & 0.147 & $0.129 *$ \\
\hline child1y & $0.236^{* * *}$ & $0.312^{* * *}$ & $0.322^{* * *}$ & $0.279 * * *$ & $0.145^{* *}$ & $0.262^{* * *}$ & $0.391 * * *$ & $0.488^{* * *}$ & $0.526^{* * *}$ & 0.037 & 0.077 \\
\hline diffhh & 0.018 & 0.016 & -0.05 & 0.031 & -0.019 & -0.045 & $0.105^{*}$ & 0.037 & 0.007 & $0.070^{*}$ & 0.037 \\
\hline F30-50 & 0.009 & $-0.097 * *$ & 0.062 & -0.067 & -0.021 & 0.012 & -0.014 & $0.147^{* *}$ & 0.014 & 0.034 & 0.057 \\
\hline F50plus & $0.051^{* *}$ & 0.068 & $0.134^{* *}$ & -0.015 & -0.007 & 0.054 & -0.084 & $0.209^{* *}$ & 0.013 & 0 & 0.069 \\
\hline M18-30 & $-0.053^{* * *}$ & -0.061 & -0.024 & $-0.116^{* *}$ & $-0.100^{*}$ & -0.018 & -0.028 & -0.028 & -0.079 & -0.076 & 0.028 \\
\hline M30-50 & $-0.045^{* *}$ & $-0.125^{* * *}$ & -0.009 & -0.067 & $-0.125^{*}$ & -0.094 & -0.143 & $0.167^{* *}$ & -0.051 & -0.029 & 0.04 \\
\hline M50plus & 0.03 & 0.011 & 0.108 & -0.027 & -0.081 & 0.062 & 0.073 & $0.191 * *$ & 0.034 & -0.069 & $0.122^{*}$ \\
\hline married & 0.023 & $0.091 * *$ & 0.014 & 0.023 & 0.014 & $0.101^{* *}$ & 0.033 & -0.019 & 0.035 & -0.013 & 0.008 \\
\hline primeduc & $0.042^{* *}$ & $0.186^{* * *}$ & 0.08 & 0.054 & 0.032 & 0.076 & 0.034 & -0.093 & 0.069 & -0.012 & 0.037 \\
\hline seceduc & $0.067 * * *$ & $0.183^{* *}$ & 0.089 & 0.022 & $0.076^{*}$ & $0.212^{* * *}$ & 0.166 & -0.049 & $0.145^{* *}$ & 0.019 & 0.076 \\
\hline higheduc & $0.051^{* *}$ & $0.168 * *$ & 0.1 & 0.068 & 0.067 & $0.162 *$ & 0.096 & -0.127 & $0.138^{*}$ & -0.092 & 0.079 \\
\hline govemp & $-0.072 * *$ & -0.072 & -0.078 & 0.035 & 0.02 & 0.189* & -0.126 & -0.079 & 0.008 & -0.183 & 0.091 \\
\hline nongovemp & $-0.085^{* *}$ & -0.066 & -0.065 & -0.023 & -0.024 & 0.099 & 0.057 & -0.128 & -0.04 & $-0.221 *$ & 0.037 \\
\hline selfemp & $-0.101 * *$ & -0.125 & -0.023 & 0.008 & 0.075 & -0.034 & -0.073 & -0.23 & -0.039 & $-0.252^{*}$ & 0.007 \\
\hline epml & $-0.076^{* *}$ & $-0.100^{*}$ & -0.081 & 0.035 & -0.034 & 0.137 & -0.084 & 0.017 & -0.037 & $-0.208^{*}$ & 0.08 \\
\hline urban \& Q5 & $0.119^{* * *}$ & & & & & & & & & & \\
\hline urban \& Q4 & $0.078^{* * *}$ & & & & & & & & & & \\
\hline urban \& Q3 & 0.045 & & & & & & & & & & \\
\hline urban \& Q2 & 0.038 & & & & & & & & & & \\
\hline urban \& Q1 & 0.032 & & & & & & & & & & \\
\hline rural \& Q5 & $0.115^{* * *}$ & & & & & & & & & & \\
\hline rural \& Q4 & $0.089 * * *$ & & & & & & & & & & \\
\hline rural \& Q3 & 0.04 & & & & & & & & & & \\
\hline rural \& Q2 & 0.035 & & & & & & & & & & \\
\hline constant & $0.125^{* * *}$ & 0.09 & 0.153 & 0.138 & 0.146 & -0.111 & 0.167 & $0.246^{*}$ & 0.069 & $0.347 * *$ & 0.006 \\
\hline observations & 9475 & 1472 & 1364 & 1259 & 970 & 565 & 439 & 565 & 644 & 901 & 1296 \\
\hline
\end{tabular}

Appendix Table 2: Linear probability model results for any care in the last year in pooled sample and for wealth/urban subgroups.

Notes: ${ }^{* * *}$ significant at $1 \%,{ }^{* *}$ significant at $5 \%, *$ significant at $10 \%$. 


\begin{tabular}{|c|c|c|c|c|c|c|c|c|c|c|c|}
\hline & \multicolumn{11}{|c|}{ inpatient care in last 5 years } \\
\hline & pooled & urban \& Q5 & urban \& Q4 & arban \& Q & urban \& Q2 & urban \& Q1 & rural \& Q5 & rural \& Q4 & rural \& Q3 & rural \& Q2 & rural \& Q1 \\
\hline daily & $0.068^{*}$ & 0.004 & 0.094 & $0.343^{* * *}$ & $-0.121 *$ & $0.199 *$ & -0.207 & -0.104 & -0.059 & 0.155 & 0.147 \\
\hline vigourous & $0.054 * * *$ & 0.041 & 0.051 & 0.033 & 0.075 & 0.015 & 0.167 & $0.209 * *$ & 0.049 & -0.014 & 0.046 \\
\hline selfcare & 0.039 & -0.189 & 0.05 & $-0.181 * *$ & 0.17 & 0.183 & 0.183 & 0.177 & $0.505^{* * *}$ & $-0.242^{* * *}$ & -0.037 \\
\hline pain & $0.051^{* *}$ & $0.166^{*}$ & -0.069 & $0.109^{*}$ & 0.001 & 0.025 & 0.053 & 0.102 & -0.037 & 0.039 & $0.083^{*}$ \\
\hline cognition & $-0.049 * *$ & -0.038 & $-0.126^{* *}$ & 0.03 & -0.002 & $-0.145^{* * *}$ & -0.128 & 0.011 & -0.042 & -0.055 & $-0.073^{*}$ \\
\hline relation & 0.048 & 0.025 & 0.087 & -0.145 & 0.017 & $-0.133^{*}$ & -0.053 & -0.103 & 0.105 & 0.123 & 0.105 \\
\hline seeing & 0.005 & $0.187 * * *$ & 0.04 & -0.025 & 0.002 & 0.054 & -0.014 & -0.087 & 0.006 & -0.047 & 0.01 \\
\hline sleep & 0.007 & -0.039 & 0.013 & $0.090 *$ & $-0.099 *$ & -0.026 & -0.047 & 0.123 & -0.012 & 0.03 & 0.003 \\
\hline badhealth & $0.020^{* *}$ & 0.049 & -0.026 & $0.054^{* *}$ & 0.02 & 0.048 & -0.009 & 0.015 & 0.043 & 0.008 & 0.02 \\
\hline arthritis & $0.028^{*}$ & 0.034 & 0.002 & $-0.064^{*}$ & 0.042 & 0.028 & 0.131 & 0.094 & 0.008 & $0.108^{*}$ & 0.007 \\
\hline back & -0.001 & 0.005 & 0.018 & 0.022 & 0.023 & 0.007 & $-0.086^{*}$ & $-0.081 * *$ & -0.012 & 0.023 & -0.004 \\
\hline angina & 0.006 & 0.015 & 0.008 & 0.035 & -0.017 & -0.017 & 0.077 & 0.09 & 0.04 & -0.03 & $-0.059 *$ \\
\hline asthma & $0.067^{* * *}$ & $0.133^{* * *}$ & $0.095^{*}$ & 0.016 & 0.068 & -0.024 & 0.039 & 0.058 & 0.025 & 0.098 & 0.051 \\
\hline depression & $0.156^{* * *}$ & $0.207^{*}$ & $0.245^{* *}$ & 0.039 & $0.321 * * *$ & 0.195 & $0.628^{* * *}$ & -0.158 & $0.212^{*}$ & 0.011 & 0.078 \\
\hline paranoia & 0.003 & $-0.099 *$ & -0.05 & $0.130^{* *}$ & 0.05 & -0.131 & -0.072 & -0.024 & 0.031 & $0.181^{* *}$ & 0.037 \\
\hline TB & 0.083 & 0.162 & 0.019 & 0.023 & 0.055 & 0.139 & 0.213 & 0.157 & 0.217 & 0.075 & 0.01 \\
\hline oralprob & -0.006 & -0.002 & 0.014 & -0.017 & 0.02 & 0.048 & -0.042 & $-0.095^{* *}$ & 0.029 & -0.03 & 0.014 \\
\hline accident & $0.068^{* * *}$ & $0.155^{* *}$ & 0.064 & $0.109^{*}$ & 0.045 & 0.001 & $0.253^{*}$ & 0.005 & 0.059 & -0.051 & 0.069 \\
\hline child1y & $0.190^{* * *}$ & $0.339 * * *$ & $0.314^{* * *}$ & $0.226^{* * *}$ & $0.190^{* * *} *$ & $0.113^{*}$ & $0.178^{* *}$ & $0.241^{* * *}$ & $0.140^{*}$ & -0.012 & 0.07 \\
\hline diffhh & -0.003 & -0.014 & 0.015 & -0.009 & -0.017 & -0.018 & -0.001 & -0.065 & -0.056 & 0.047 & -0.007 \\
\hline F30-50 & -0.005 & -0.02 & 0.013 & -0.054 & -0.063 & -0.047 & -0.01 & -0.012 & 0.087 & 0.044 & 0.013 \\
\hline F50plus & 0.025 & 0.023 & $0.100^{*}$ & -0.054 & -0.008 & -0.111 & $-0.190 * *$ & 0.044 & 0.094 & 0.099 & -0.009 \\
\hline M18-30 & -0.021 & $-0.052^{*}$ & 0.014 & -0.028 & 0.027 & -0.08 & -0.006 & -0.035 & -0.007 & -0.005 & -0.02 \\
\hline M30-50 & 0.002 & -0.034 & 0.038 & -0.011 & -0.004 & -0.028 & $-0.149 *$ & 0.014 & 0.057 & 0.031 & 0.059 \\
\hline M50plus & 0.036 & 0.042 & 0.003 & 0.021 & -0.028 & -0.068 & -0.05 & 0.083 & $0.151^{*}$ & 0.092 & 0.04 \\
\hline married & 0.018 & 0.028 & 0.04 & -0.005 & 0.016 & $0.077 * *$ & $0.104^{*}$ & 0.078 & 0.012 & -0.048 & -0.024 \\
\hline primeduc & 0.003 & 0.061 & -0.084 & 0.017 & 0.011 & $0.129 * * *$ & -0.064 & -0.051 & 0.015 & 0.006 & 0.025 \\
\hline seceduc & 0.015 & $0.075^{*}$ & -0.069 & 0.01 & 0.036 & -0.02 & -0.036 & 0 & 0.089 & 0.047 & 0.012 \\
\hline higheduc & $0.047 * *$ & $0.124 * * *$ & 0.001 & 0.044 & 0.028 & 0.139 & -0.038 & -0.023 & 0.039 & 0.039 & -0.051 \\
\hline govemp & -0.041 & -0.052 & -0.027 & -0.005 & -0.047 & -0.09 & -0.091 & -0.108 & 0.095 & -0.004 & -0.029 \\
\hline nongovemp & -0.037 & -0.043 & 0.013 & -0.025 & -0.043 & -0.127 & -0.071 & $-0.149 *$ & 0.06 & 0.044 & -0.043 \\
\hline selfemp & $-0.047^{*}$ & $-0.102^{*}$ & 0.033 & 0.054 & $-0.106^{*}$ & -0.136 & 0.185 & -0.127 & 0.029 & -0.063 & -0.053 \\
\hline epml & -0.016 & -0.031 & 0.032 & 0.048 & -0.028 & -0.09 & $-0.133^{*}$ & -0.04 & $0.119^{*}$ & 0.048 & -0.015 \\
\hline urban \& Q5 & $0.072^{* * *}$ & & & & & & & & & & \\
\hline urban \& Q4 & $0.038^{*}$ & & & & & & & & & & \\
\hline urban \& Q3 & 0.02 & & & & & & & & & & \\
\hline urban \& Q2 & 0.006 & & & & & & & & & & \\
\hline urban \& Q1 & 0.017 & & & & & & & & & & \\
\hline rural \& Q5 & $0.092^{* * *}$ & & & & & & & & & & \\
\hline rural \& Q4 & $0.077 * * *$ & & & & & & & & & & \\
\hline rural \& Q3 & $0.040 *$ & & & & & & & & & & \\
\hline rural \& Q2 & 0.017 & & & & & & & & & & \\
\hline constant & 0.05 & 0.038 & 0.056 & 0.043 & 0.065 & 0.13 & $0.323^{* *}$ & $0.231 *$ & -0.088 & 0.029 & 0.097 \\
\hline observations & 9475 & 1472 & 1364 & 1259 & 970 & 565 & 439 & 565 & 644 & 901 & 1296 \\
\hline
\end{tabular}

Appendix Table 3: Linear probability model results for inpatient care in the last 5 years in pooled sample and for wealth/urban subgroups.

Notes: *** significant at $1 \%$, ** significant at $5 \%$, * significant at $10 \%$. 


\section{References}

Bago d'Uva, T., Jones, A.M., Van Doorslaer, E. Measurement of horizontal inequity in health care utilisation using European panel data. Journal of Health Economics 2009, 28, 280-289.

Bago d'Uva, T., Lindeboom, M., O'Donnell, O., Van Doorslaer, E. Education-related inequity in healthcare with heterogeneous reporting of health. Journal of the Royal Statistical Society: Series A (Statistics in Society) 2011, 174, 639-664.

Blinder, A.S. Wage discrimination: Reduced form and structural estimates. Journal of Human Resources 1973, 8, 436-455.

Capuno, J.J. Social health insurance for the poor: programs of the Philippines and Vietnam. Philippine Journal of Development 2006, 61, 211-240.

Erreygers, G. Correcting the concentration index. Journal of Health Economics 2009, 28, 504-515.

Erreygers, G.,Van Ourti, T. Measuring socioeconomic inequality in health, health care and health financing by means of rank-dependent indices: A recipe for good practice. Journal of Health Economics 2011, 30, 685-694.

Filmer, D., Pritchett, L.H. Estimating wealth effects without expenditure data--or tears: An application to educational enrolments in states of India. Demography 2001, $38,115-132$.

Fleurbaey, M., Schokkaert, E. Unfair inequalities in health and health care. Journal of Health Economics 2009, 28, 73-90.

Fleurbaey, M., Schokkaert, E. Equity in health and health care. CORE Discussion Paper 2011/26 2011, Université Catholique de Louvain, Louvain-la-Neuve.

Goddard, M.,Smith, P. Equity of access to health care services:: Theory and evidence from the UK. Social Science \& Medicine 2001, 53, 1149-1162.

Gravelle, H. Measuring income related inequality in health: Standardisation and the partial concentration index. Health Economics 2003, 12, 803-819.

Huber, H. Decomposing the causes of inequalities in health care use: A microsimulations approach. Journal of Health Economics 2008, 27, 1605-1613. 
Jones, A.M., Rice, N., Robone, S., Dias, P.R. Inequality and polarisation in health systems' responsiveness: A cross-country analysis. Journal of Health Economics 2011, 30, 616-625.

Jones, A., López Nicolás, Á. Allowing for heterogeneity in the decomposition of measures of inequality in health. Journal of Economic Inequality 2006, 4, 347365.

Lu, J.R., Leung, G.M., Kwon, S., Tin, K.Y.K., Van Doorslaer, E., O'Donnell, O. Horizontal equity in health care utilisation evidence from three high-income Asian economies. Social Science \& Medicine 2007, 64, 199-212.

Moussavi, S., Chatterji, S., Verdes, E., Tandon, A., Patel, V., Ustun, B. Depression, chronic diseases, and decrements in health: Results from the world health surveys. Lancet 2007, 370, 851-858.

Neumark, D. Employers discriminatory behavior and the estimation of wage discrimination. Journal of Human Resources 1988, 23, 279-295.

Oaxaca, R., Ransom, M. On discrimination and the decomposition of wage differentials. Journal of Econometrics 1994, 61, 5-21.

Oaxaca, R. Male-female wage differentials in urban labor markets. International Economic Review 1973, 14, 693-709.

Obermann, K., Jowett, M.R., Alcantara, M.O.O., Banzon, E.P., Bodart, C. Social health insurance in a developing country: The case of the Philippines. Social Science \& Medicine 2006, 62, 3177-3185.

O'Donnell, O., Van Doorslaer, E., Rannan-Eliya, R.P., Somanathan, A., Adhikari, S.R., Harbianto, D., Garg, C.C., Hanvoravongchai, P., Huq, M.N., Karan, A., Leung, G.M., Ng, C.W., Pande, B.R., Tin, K., Tisayaticom, K., Trisnantoro, L., Zhang, Y., Zhao, Y. The incidence of public spending on healthcare: Comparative evidence from Asia. World Bank Economic Review 2007, 21, 93-123.

O’Donnell, O., Van Doorslaer, E., Wagstaff, A., Lindelöw, M. Analyzing health equity using household survey data: a guide to techniques and their implementation, World Development Institute, World Bank, Washington DC, 2008.

Sutton, M. Vertical and horizontal aspects of socio-economic inequity in general practitioner contacts in Scotland. Health Economics 2002, 11, 537-549. 
Van Doorslaer, E., Koolman, X., Jones, A.M. Explaining income-related inequalities in doctor utilisation in Europe. Health Economics 2004, 13, 629-647.

Van Doorslaer, E., O'Donnell, O. Measurement and explanation of inequality in health and health care in low-income settings, In: McGillivray, M, I Dutta and D Lawson (Eds) Health inequality and development, Studies in Development Economics and Policy, Palgrave MacMillan, Basingstoke, 2010, Chapter 2, 20-44.

Van Doorslaer, E., Wagstaff, A., van der Burg, H., Christiansen, T., De Graeve, D., Duchesne,I., Gerdtham, U.G., Gerfin, M., Geurts, J., Gross, L., Häkkinen, U., John, J., Klavus, J., Leu, R.E., Nolan, B., O’Donnell, O., Propper, C., Puffer, F., Schellhorn, M., Sundberg, G., Winkelhake, O. Equity in the delivery of health care in Europe and the US. Journal of Health Economics 2000, 19, 5, 553-58.

Wagstaff, A. ,Van Doorslaer, E. Measuring and testing for inequity in the delivery of health care. Journal of Human Resources 2000, 35, 716-733.

Wagstaff, A., Van Doorslaer, E., Watanabe, N. On decomposing the causes of health sector inequalities with an application to malnutrition inequalities in Vietnam. Journal of Econometrics 2003, 112, 207-223.

Wagstaff, A. Correcting the concentration index: A comment. Journal of Health Economics 2009, 28, 516-520.

Xu, K., Ravndal, F., Evans, D.B., Carrin, G. Assessing the reliability of household expenditure data: Results of the world health survey. Health Policy 2009, 91, $297-$ 305. 